\title{
Reinterpretation of the Taxonomic Position of Xanthomonas maltophilia and Taxonomic Criteria in This Genus Request for an Opinion
}

\author{
ELRITHA VAN ZYL AND P. L. STEYN* \\ Department of Microbiology and Plant Pathology, University of Pretoria, \\ Pretoria 0002, Republic of South Africa
}

\begin{abstract}
The inclusion of "Pseudomonas maltophilia" Hugh 1981 in the genus Xanthomonas as Xanthomonas maltophilia (Hugh 1981) Swings et al. 1983 is questioned in view of the significant differences between these two taxa. This reclassification is not acceptable if practical means of differentiation in this genus are considered. The proposed alteration of the description of the genus Xanthomonas is also questionable because of the implications for everyday phytobacteriology. In view of the natural similarities, as well as the profound differences, between $X$. maltophilia and the genus Xanthomonas, we propose that a new genus should be created for $X$. maltophilia, which could be placed together with the genus Xanthomonas in a separate natural group.
\end{abstract}

The taxonomic position of Xanthomonas maltophilia (Hugh 1981) Swings et al. 1983 has been the subject of much debate $(1,7,16,18,25,26,28,35,37,38)$. Initially isolated from pleural fluid in 1943 and named "Bacterium bookerii,' this ubiquitous bacterium was reclassified as "Pseudomonas maltophilia" by Hugh and Ryschenkow in 1961 (15). As " $P$. maltophilia" and species of the genus Xanthomonas exhibit substantial levels of rRNA homology (28), it appeared to be appropriate to assign this species to the genus Xanthomonas (26). A number of arguments in the literature also support this view, and consequently Swings et al. (37) proposed the transfer of $P$. maltophilia Hugh 1981 to the genus Xanthomonas as Xanthomonas maltophilia (Hugh 1981) comb. nov.

In view of the significant differences between these two taxa, this reclassification remains questionable (27), partly because of the redefinition of the genus Xanthomonas that would be required to accommodate $X$. maltophilia $(1,26)$.

As our own results (39) also argue against inclusion of $X$. maltophilia in the genus Xanthomonas, the purposes of this paper are to question some of the assumptions made by Swings et al. (37), to summarize the latest information on this subject, and to request an opinion.

The arguments below proceed from the reclassification proposed by Swings et al. (37) and should be considered together with their corresponding discussions.

DNA-rRNA hybridization. The taxonomic value and reliability of DNA-rRNA hybridization for classifying bacteria on generic and suprageneric levels have been demonstrated by several workers $(4-8,12,22)$. However, the data discussed below from the reclassification proposed by Swings et al. (37) are confusing. Although Swings et al. (37) referred to an extensive DNA-rRNA hybridization study of the genus Pseudomonas by De Vos and De Ley (in press at that time), different melting temperature $\left[T_{m(e)}\right]$ ranges were reported by these authors for exactly the same Xanthomonas strains. Swings et al. (37) reported a range of 78.8 to $81.5^{\circ} \mathrm{C}$, while $\mathrm{De}$ Vos and De Ley (7) found a range of 80.0 to $81.5^{\circ} \mathrm{C}$ for the same 27 Xanthomonas strains when they used identical

\footnotetext{
* Corresponding author.
}

conditions and the same Xanthomonas campestris NCPPB $528^{\mathrm{T}}(\mathrm{T}=$ type strain) reference $\mathrm{rRNA}$. Therefore, the range determined for $X$. maltophilia by Swings et al. (37) (76.5 to $\left.78.0^{\circ} \mathrm{C}\right)(7,37)$ almost overlapped the range for the genus Xanthomonas, whereas De Vos and De Ley (7) found that $X$. maltophilia was removed from the genus Xanthomonas at a $T_{m(e)}$ of $3^{\circ} \mathrm{C}$ under the conditions used. This placed the $X$. maltophilia cluster close to the genus Xanthomonas, but still not in the genus. This finding was confirmed by Van den Mooter and Swings (38), who found an X. maltophilia $T_{m(e)}$ range of 77 to $78^{\circ} \mathrm{C}$, while the $T_{m(e)}$ values for the rest of the Xanthomonas species ranged from 79 to $82^{\circ} \mathrm{C}$. Also, when reference rRNAs from three Pseudomonas spp. type strains were used, $X$. maltophilia was located close to the genus Xanthomonas, but was never included in the same similarity cluster (7).

As the level of hybrid formation depends not only on the actual sequence homology, but also on the size of the genome, its state of replication, and the number of rRNA cistrons per genome, rRNA similarity should be expressed by two parameters, percentages of rRNA binding and melting points $\left[T_{m(e)}\right.$ values] of DNA-rRNA hybrids $(19,32)$. Swings et al. (37) did not mention the percentage of rRNA binding in their study. Although the percentage of rRNA binding might not be a direct measure of rRNA cistron homology, it is a useful parameter for separating taxa with the same $T_{m(e)}$ value (8); in this case percentage of rRNA binding removed $X$. maltophilia even further from the extremely tight Xanthomonas cluster when the values were plotted on a similarity map (7).

As DNA-rRNA hybridization data were the first indicators that " $P$. maltophilia" might be transferred to the genus Xanthomonas (28), it is interesting to note the opinions concerning the DNA-rRNA approach described below. According to Woese et al. (44), the DNA-rRNA approach offers no advantage over DNA-DNA hybridization (which revealed low levels of DNA similarity among Pseudomonas species [18]) when it comes to groupings at the generic level and has the disadvantage that it samples only one or two genes. According to Sneath (32), the reliability of the DNArRNA approach has not yet received critical study with a sound theoretical basis. Some fundamental questions have 
also arisen because many groups based on rRNA analysis are not easily definable in terms of phenotypic similarities, raising doubt about the practicality of a phylogenetic classification based on rRNA analysis (22).

DNA-DNA homology. At present, DNA-DNA homology is widely accepted as an expression of genetic relatedness (16). However, membrane competition experiments have revealed very low levels of DNA similarity among Pseudomonas species belonging to the five different rRNA subgroups (18). Interspecies similarity values are in the 5 to $20 \%$ range, and the average DNA similarity values between species belonging to different rRNA similarity clusters are even lower (not more than 1 to $2 \%$ ) (18). For $X$. maltophilia the percentages of similarity with labeled DNAs from $X$. campestris strains range from 22 to $37 \%$ (16) or from 1 to $16 \%$ when the S1 nuclease method is used (18). Such low values are at the border of or below the sensitivity of this method (37) and are very difficult to interpret. According to Johnson (17), values in the lower homology range (20 to $60 \%$ DNA homology) indicate species which are often quite distinct phenotypically from the species with which they are compared, although they may be regarded as closely related. Unfortunately, there is currently no satisfactory phylogenetic definition of a genus (42).

The low levels of DNA similarity between Pseudomonas species have far-reaching implications for taxonomy and phylogenetic relationships in this group, when it is considered that the DNA-DNA approach actually represents (an average of) the entire genome and not merely a few genes in the genome (44). For classification purposes it is now also considered necessary to calibrate techniques for the differentiation of strains against DNA-DNA hybridization, the conventional method used for the delineation of species (40). Furthermore, it is suggested that minimal standards for the genus Xanthomonas should include tests for generic identity (45). However, it is possible that DNA-DNA homology analyses may not reveal the elements of a genome which are taxonomically significant (21). This again accentuates the importance of a polyphasic approach that also incorporates phenotypic properties $(22,45)$.

DNA-DNA hybridization data divided Pseudomonas rRNA group V strains into two subgroups, an $X$. maltophilia subgroup and an $X$. campestris subgroup, with substantial heterogeneity among the strains in each subgroup (18). Ikemoto et al. (16) also observed heterogeneity among $X$. maltophilia strains and delineated five clusters on the basis of DNA-DNA homology data. There was also a difference between methionine-requiring and methionine-nonrequiring strains of $X$. maltophilia with respect to DNA-DNA homology (16).

$\mathbf{G}+\mathbf{C}$ contents. The guanine-plus-cytosine $(\mathrm{G}+\mathrm{C})$ range determined for $X$. maltophilia (63 to $67.5 \mathrm{~mol} \%$ ) fits well into the Xanthomonas range (63 to $71 \mathrm{~mol} \%$ ) (1), and although it also fits into the Pseudomonas range (58 to $70 \mathrm{~mol} \%$ ) (26), these values are not inconsistent with inclusion of $X$. maltophilia in the genus Xanthomonas. However, it is also important to bear in mind that although these $G+C$ values are very similar for related organisms, the reverse is not true; two organisms with similar $\mathrm{G}+\mathrm{C}$ contents are not necessarily related, as the $\mathrm{G}+\mathrm{C}$ values do not take into account the linear arrangement of the nucleotides in the DNAs $(3,17)$.

Comparative enzymology. According to Swings et al. (37), “'both ' $P$. maltophilia' and Xanthomonas are unusual in that they lack NADP-linked dehydrogenases and possess NADspecific prephenate and arogenate dehydrogenases for tyrosine biosynthesis." Referring to the original article on this topic (2), we learned that rRNA homology groups I, IV, and $\mathrm{V}$ of the genus Pseudomonas all lack activity for arogenateNADP dehydrogenase, while groups $I$ and $V$ also lack prephenate-NADP dehydrogenase activity. As both groups I and $\mathrm{V}$ also possess NAD-specific prephenate and arogenate dehydrogenases for tyrosine biosynthesis (2), X. maltophilia and the genus Xanthomonas are not so unusual in this regard. Groups I and V are separated by comparing the relative allosteric sensitivities of NAD-dependent dehydrogenases (2). Unfortunately, results for $X$. maltophilia were not included in the comparison of the sensitivities of the NAD-dependent dehydrogenases to tyrosine inhibition, and only one Pseudomonas species (Pseudomonas gardneri) was grouped with all of the Xanthomonas species studied (2).

The control pattern for the enzyme 3-deoxy-D-arabinoheptulosonate-7-phosphate synthetase is a useful indicator of taxonomic relationships at about the level of genera (43). The occurrence of this unique control mechanism in $X$. maltophilia, as well as in species of the genus Xanthomonas, indeed supports a close taxonomic relationship between these two taxa $(37,43)$, but it has to be remembered that the comparative allostery of 3-deoxy-D-arabinoheptulosonate-7phosphate synthetase alone does not unambiguously establish group placement (43).

Ubiquinones. Swings et al. (37) state that both $X$. maltophilia and the genus Xanthomonas contain ubiquinones with eight isoprene units (Q-8), whereas all other Pseudomonas strains tested generally contain ubiquinones with nine isoprene units (Q-9) as major components. In our opinion this does not reflect the true situation correctly. Oyaizu and Komagata (24) examined the quinone systems of 75 Pseudomonas strains and divided them into nine groups according to this characteristic, as well as fatty acid composition. Of the nine groups determined, only group I (corresponding to rRNA homology group I) species contain a Q-9 system, while five groups of named pseudomonads contain $\mathrm{Q}-8$ quinone systems. These groups include a Pseudomonas solanacearum group (rRNA group II), a "Pseudomonas acidovorans" group (rRNA group III), X. maltophilia (rRNA group V), Pseudomonas avenae, and Pseudomonas palleronii (rRNA group III). The three other groups contain $\mathrm{Q}-10$ systems (24).

On the basis of ubiquinone content, the $X$. maltophiliaXanthomonas group is not as unusual as implied by Swings et al. (37).

Cellular fatty acid composition. Quantitative differences in fatty acids were found between the $X$. maltophilia strains that do not require methionine and the methionine-requiring strains of this species, although both groups have almost the same kinds of fatty acids (16). On the basis of cellular fatty acid compositions, a similarity value of $82 \%$ was calculated for the two groups (16). From the data of Ikemoto et al. (16), it is interesting to note that $X$. maltophilia strains which do not require methionine also share relatively high mean percentages of $i-C_{16: 0}$ and $C_{17: 0}$ fatty acids with two of the three Xanthomonas strains studied and have values that are considerably higher than the percentages determined for methionine-requiring strains of $X$. maltophilia. On the other hand, Xanthomonas oryzae has a fatty acid composition quite different from that of $X$. maltophilia (16).

Phage typing. Phage typing studies provided evidence for a relationship between $X$. maltophilia and the genus Xanthomonas (37). However, this technique is not very successful as a taxonomic tool in the genus Xanthomonas, mainly because of a lack of specificity $(1,10)$. 
In addition, temperate phages have been found in $X$. maltophilia (26), while nothing of this nature has been reported for the genus Xanthomonas.

Growth and pigments. The colonies of Xanthomonas species are distinctively yellow, and this pigmentation is very important in the presumptive identification of these organisms $(35,45)$. It has been suggested that these pigments (xanthomonadins) might serve as adequate chemotaxonomic markers for the genus Xanthomonas (35). X. maltophilia cultures do not exhibit the yellow mucoid growth typical of the genus Xanthomonas, and its pigments are not xanthomonadins or closely related to the xanthomonadins that have been studied $(26,35,37)$.

Nonpigmented Xanthomonas strains do exist, but evidence in the literature indicates that pigmented forms exist for all of the nonpigmented Xanthomonas species which occur naturally $(29-31,36)$.

Swings et al. (37) reported that some $X$. maltophilia strains characteristically form brownish grey water-soluble pigments, which have also been observed in six pathovars of $X$. campestris. Gilardi (11) believes that the brown coloration of the culture medium that is associated with $X$. maltophilia and has been previously described as a pigment is probably due to a secondary chemical reaction among extracellular products which react to form the brown color.

When grown on media containing usable carbohydrates, most Xanthomonas strains produce characteristic extracellular polysaccharides or xanthan gums, resulting in very mucoid colonies $(1,37)$. The growth of $X$. maltophilia is shiny, but not mucoid (37). This presents a practical problem, as slime formation has some value in screening Xanthomonas cultures (9). Except for Xanthomonas albilineans, $99 \%$ of the $X$. campestris strains and $100 \%$ of the strains of five other Xanthomonas phena tested by Van den Mooter and Swings (38) produced mucoid colonies. Only $14 \%$ of the $X$. maltophilia strains were mucoid (38).

Niches. All species currently included in the genus Xanthomonas are highly specialized plant pathogens (1), while at present nothing is known about the phytopathogenic capacity of $X$. maltophilia strains (37). Most $X$. maltophilia strains have been isolated from clinical specimens; $X$. maltophilia is the second most frequently isolated Pseudomonas species in clinical laboratories (26). Strains of this species appear to be opportunistic human pathogens (26). There is currently no evidence of any Xanthomonas species associated with human infections.

$X$. maltophilia strains are also found in frozen food, milk, and water, while $X$. maltophilia predominates over other pseudomonads in the rhizospheres of several cultivated plants, probably because of the excretion of S-containing amino acids by the roots (26). However, for Xanthomonas species the minimum growth temperature is above $5^{\circ} \mathrm{C}(1)$. Xanthomonads have occasionally been detected in runoff water and ditches around fields of infected plants, but data indicate that survival in this situation is short (1). Saprophytic survival in soil is also unusual for Xanthomonas species (1). However, two pathovars of $X$. campestris are known to spend the interseasonal time epiphytically (1).

Other morphological, physiological, and biochemical characteristics. From the literature we know that $X$. maltophilia and the genus Xanthomonas share a number of morphological, physiological, and biochemical characteristics (37). Swings et al. (37) calculated a simple matching similarity coefficient $\left(S_{\mathrm{SM}}\right)$ of approximately $75 \%$ between these two taxa from the available phenotypic data.

Despite the high similarity value $\left(S_{\mathrm{SM}}\right)$ of $79 \%$ calculated for $X$. maltophilia NCPPB 1974 in a phenotypic study in which 53 standard phenotypic tests were used and with data agreeing well with the data available in the literature, $X$. maltophilia NCPPB 1974 was less closely related to the Xanthomonas group than the majority of Pseudomonas strains studied were (39). This finding was confirmed by the results of a numerical analysis of the electrophoretic protein patterns of the same strains, in which a correlation value of $r=0.65$ was determined between $X$. maltophilia NCPPB 1974 and the larger Pseudomonas-Xanthomonas cluster (39).

In an extensive phenotypic study of Xanthomonas strains, Van den Mooter and Swings (38) placed $X$. maltophilia in phenon 1 of their dendrogram; Pseudomonas pictorum and unidentified strain LMG 949 were the only other strains included in this phenon as remote neighbors. Strain LMG 949 deviates in several characteristics from the new generic description of the genus Xanthomonas given in the same paper (38). An $S_{\mathrm{SM}}$ value of $65 \%$ was reported between phenon 1 and four other Xanthomonas phena (namely, Xanthomonas fragariae, $X$. albilineans, Xanthomonas axonopodis, and Xanthomonas populi) (38). However, X. maltophilia was phenotypically less closely related to the four Xanthomonas phena mentioned above than to Xylophilus ampelinus, which is not a member of the genus Xanthomonas at all (38).

The number of polar flagella is an important taxonomic characteristic (26). The presence of a single polar flagellum is an important characteristic of the genus Xanthomonas. Very rarely cells with two polar flagella occur (1). On the other hand, $X$. maltophilia is multitrichous $(26,37)$.

At present no pili or fimbriae have been described for the genus Xanthomonas (1), while polarly inserted pili or fimbriae have been described for $X$. maltophilia (26).

According to the present generic definition of the genus Xanthomonas, no nitrate reduction occurs (1). X. maltophilia strains reduce nitrates to nitrites $(20,37)$.

According to Swings et al. (37), some of the characteristics shared by $X$. maltophilia and the genus Xanthomonas are acid production from (among other compounds) lactose, fructose, and maltose, as well as hydrolysis of esculin. According to Bradbury (1), he actually found variation in these reactions. For acid production from lactose and maltose three Xanthomonas species gave negative reactions, while 11 to $89 \%$ of the $X$. campestris strains were positive; for acid production from fructose, two Xanthomonas species gave negative reactions, while three species were positive. Tests for hydrolysis of esculin also resulted in varied reactions; three Xanthomonas species were positive, and one Xanthomonas species was negative (1).

Other differences between $X$. maltophilia and the genus Xanthomonas include the production of lysine decarboxylase, starch hydrolysis, resistance to antibiotics (especially streptomycin, kanamycin, tetracycline, and chloramphenicol), dyes, and metals, and tolerance to $4 \% \mathrm{NaCl}(37,38)$. According to the generic definition, Xanthomonas growth is inhibited by $0.1 \%$ triphenyltetrazolium chloride (1). All of the $X$. maltophilia strains tested by Van den Mooter and Swings (38) grew on $0.1 \%$ triphenyltetrazolium chloride.

From the data discussed above it is clear that there are profound differences between $X$. maltophilia and the genus Xanthomonas, differences which are not without substantial practical implications for the already complex taxonomic structure and identification system in the genus Xanthomonas.

Additional remarks. Since the publication of the proposal for the transfer of " $P$. maltophilia" to the genus Xanthomo- 
nas (37), the considerations discussed below have appeared in favor of or as arguments against this inclusion.

(i) Oligonucleotide cataloging of 16S rRNA. $S_{\mathrm{AB}}$ analysis of oligonucleotide cataloging has shown that $X$. maltophilia and "its close relatives (i.e., the xanthomonads)" cluster peripherally with the fluorescent pseudomonas group (Pseudomonas fluorescens, Pseudomonas aeruginosa, Pseudomonas syringae, etc.) in particular (44). However, catalogs of members of the $X$. maltophilia group also show that these organisms have a remarkable number of oligonucleotides in common with group II species (Comamonas acidovorans, Pseudomonas testosteroni, Pseudomonas cepacia, etc.) (44).

(ii) Respiratory chain. Difference spectra at the liquid air temperature have shown that there is a slight shoulder for the genus Xanthomonas at $549 \mathrm{~nm}$, suggesting that these organisms have a very small cytochrome $c$ content. The difference spectra for $P$. syringae and $X$. maltophilia are very similar, but do not have any noticeable peak or shoulder at or near $549 \mathrm{~nm}(1)$.

(iii) Growth factor requirement. Many Xanthomonas strains require growth factors, usually amino acids such as methionine and/or glutamic acid. Nicotinic acid is occasionally required (1). X. maltophilia has a requirement for methionine, although strains of $X$. maltophilia which do not require methionine have been described (16). These methionine-requiring and methionine-nonrequiring strains of $X$. maltophilia differ from each other with respect to phenotypic characteristics, cellular fatty acid composition, DNA base composition, and DNA-DNA hybridization and can be separated into two clusters on the basis of methionine requirement and some other properties (16). It is also noteworthy that the requirement for methionine depends upon the carbon compounds used (16). Although it is likely that the genus Pseudomonas will be reserved in the future for species that do not require growth factors, there are also a few Pseudomonas species that require the addition of organic growth factors. For example, Pseudomonas diminuta also needs methionine, while growth factor-requiring strains of Pseudomonas caryophylli and $P$. syringae are occasionally encountered in nature (26).

(iv) Metabolism of aromatic compounds. On the basis of the dehydratases of the two pathways to phenylalanine, five rRNA-DNA hybridization groups have been distinguished. $X$. maltophilia was assigned to group $\mathrm{V}$ together with other Xanthomonas strains. However, group $\mathrm{V}$ could not be distinguished from group Ib by using these enzymes (1).

(v) Glycoside hydrolases. Hayward (13) demonstrated the presence of $\alpha$-glucosidase, $\beta$-glucosidase, $\beta$-galactosidase, and $\beta$-xylosidase activities in most of the 39 Xanthomonas strains which he examined, as well as in $X$. maltophilia (" $P$. maltophilia") alone among the Pseudomonas species.

(vi) Cell walls. Both $X$. maltophilia and members of the genus Xanthomonas have a high rhamnose content, a low 2-keto-3-deoxyoctonate content, $D$-galacturonic acid, and no heptoses in their cell walls. However, all of the Xanthomonas strains examined so far for these characteristics are members of one species, $X$. campestris (1). An interesting feature of the lipopolysaccharide of $X$. maltophilia is the presence of a pentose derivative that has been identified as 3-O-methyl-L-xylose, which thus far has not been found in other bacteria except Rhodopseudomonas viridis (26).

(vii) Exoproducts. High degrees of similarity $(>90 \%)$ among the electropherograms of the exoproducts of 31 Pseudomonas strains, including (among others) $X$. malto- philia, $P$. aeruginosa, $P$. fluorescens, $P$. alcaligenes, etc., have been shown by polyacrylamide gel electrophoresis (41)

(viii) Asparagine. Starr (34) and Dye (9) have reported that asparagine is inadequate as a sole source of carbon and nitrogen for xanthomonads. Bradbury (1) included this property in the definition of the genus Xanthomonas, and this characteristic is presently used as a diagnostic test for the genus Xanthomonas, since yellow members of the Enterobacteriaceae and many Pseudomonas species grow with asparagine as a sole source of both carbon and nitrogen (1). In a previous study (39) we found that $X$. maltophilia NCPPB 1974 and Pseudomonas hibiscicola NCPPB 1683 are capable of growing with $0.2 \%$ asparagine as a sole source of $\mathrm{C}$ and $\mathrm{N}$. Using a totally different medium and $0.1 \%$ asparagine, Van den Mooter and Swings (38) recorded a negative reaction for this test.

To summarize, at present the characteristic determinative tests for the genus Xanthomonas are as follows: Gram reaction, cell morphology, flagellar insertion (single, polar), oxygen requirement, absence of nitrate reductase, no denitrification, triphenyltetrazolium chloride sensitivity, inability to use asparagine as a sole source of carbon and nitrogen, requirement for specific growth factors, and production of a distinctive pigment by a majority of the strains (45). Bradbury (1) also added plant pathogenicity. In addition, according to Young et al. (45), "unless these criteria are always met, further confusion can be expected, particularly between the genera Xanthomonas and Pseudomonas, as the number of species described increase."

On the other hand, $X$. maltophilia is multitrichous and reduces nitrates, and its growth is not inhibited by $0.1 \%$ triphenyltetrazolium chloride. It may be able to grow with asparagine as a sole source of carbon and nitrogen, while there are strains that do not require methionine as a growth factor. The pigments of $X$. maltophilia are not xanthomonadins. At present this organism is not regarded as a plant pathogen; on the contrary, it is associated with human infections, survives saprophytically in several niches, and occurs free living in nature. It does not produce the characteristic xanthan gums, and its colonies differ from those of most other Xanthomonas species by their umbonate form (38). Pili or fimbriae are present. A low level of correlation in electrophoretic protein patterns has been demonstrated. DNA-DNA and DNA-rRNA hybridization results can be interpreted in various ways, but to us these data also points to inclusion of the two taxa in a natural group as close relatives, rather than inclusion in the same genus. Unlike other xanthomonads, $X$. maltophilia grows at $37^{\circ} \mathrm{C}$, tolerates $4 \% \mathrm{NaCl}$, and is resistant to several antibiotics, dyes, and metals. Oxidase activity was present in $71 \%$ of the $X$. maltophilia strains studied by Van den Mooter and Swings (38), while except for $19 \%$ of the $X$. campestris strains, oxidase activity was absent in all other Xanthomonas phena (38). As discussed above, several properties are also shared with Pseudomonas species.

Swings et al. (37) proposed an improved definition of the genus Xanthomonas, namely, that "all Xanthomonas strains tested fall in the $T_{m(e)}$ range from 76 to $81^{\circ} \mathrm{C}$ when their DNAs are hybridized with labeled rRNA from type strain $X$. campestris pv. campestris NCPPB 528." However, it is not clear to what extent this $T_{m(e)}$ range was lowered mainly to include $X$. maltophilia.

In our view the question of the reclassification of $X$. maltophilia is closely linked to the taxonomic situation in the genus Xanthomonas and confirms the need for minimal standards for this genus (45). At present, there are many 
arguments in favor of a more phylogenetically based system of classification rather than a determinative system. However, it will be a major setback for everyday phytobacteriology, in which speed, cost effectiveness, and the availability of sophisticated apparatus are often issues, if an improved definition of the genus Xanthomonas is based upon characteristics of phylogenetic value which cannot be readily determined or repeated by workers in less wellequipped laboratories. For example, Vauterin et al. (40) are of the opinion that in a general taxonomic environment there is no reason to assign crucial importance to a single phenotypic feature, such as plant pathogenicity. However, plant pathogenicity and host specificity play a very important role in the presumptive identification of xanthomonads by plant pathologists, and provision must be made for this feature, as well as several other practical means of differentiation, in the proposed improved definition and the promulgation of minimal standards for the genus Xanthomonas. Although modern bacterial systematists cannot be expected to work with an artificial type of classification for practical purposes only, a natural classification without practical implications is also not acceptable (40). A classification that is of little use to microbiologists, no matter how fine a scheme or who devised it, will soon be ignored or significantly modified (36). It is completely impracticable to define genera solely on the basis of phylogenetic data. Genera need to be characterized by using phenotypic properties, even if the choice of phenotypic markers might change with the development of better tests (23). Furthermore, published descriptions of taxa should preserve the ability to identify strains to species level in laboratories that rely mainly on phenotypic properties (45).

The same argument applies to $X$. maltophilia. Although evidence of a more phylogenetic nature suggests that there is a close relationship between $X$. maltophilia and the genus Xanthomonas, the inclusion of this species in the genus Xanthomonas is not acceptable on practical grounds. With an improved description of the genus Xanthomonas (38), $X$. maltophilia is so often the exception to the rule that its inclusion in the genus Xanthomonas does not promote taxonomic stability in this genus. Instead, and contradictory to the aims of taxonomy, it leads to confusion, complicating the task of classifying and identifying field isolates of this species.

In order to provide for the natural similarities, as well as the significant differences discussed here, we propose that a separate genus should be created for $X$. maltophilia, which could be placed with the genus Xanthomonas in the same natural group.

\section{ACKNOWLEDGMENTS}

We are indebted to the Tobacco Board of South Africa for financial support.

We thank J. J. Joubert for supplying the computer program for numerical analysis of electropherograms and J. I. Maritz for the modification and implementation thereof.

\section{REFERENCES}

1. Bradbury, J. F. 1984. Genus II. Xanthomonas, p. 199-120. In N. R. Krieg and J. G. Holt (ed.), Bergey's manual of systematic bacteriology, vol. 1. The Williams \& Wilkens Co., Baltimore.

2. Byng, G. S., R. J. Whitaker, R. L. Gherna, and R. A. Jensen. 1980. Variable enzymological patterning in tyrosine biosynthesis as a new means of determining natural relatedness among Pseudomonadaceae. J. Bacteriol. 144:247-257.
3. De Ley, J. 1968. DNA base composition and hybridization in the taxonomy of phytopathogenic bacteria. Annu. Rev. Phytopathol. 6:63-90.

4. De Ley, J., P. Segers, and M. Gillis. 1978. Intra- and intergeneric similarities of Chromobacterium and Janthinobacterium ribosomal ribonucleic acid cistrons. Int. J. Syst. Bacteriol. 28:154 168.

5. De Smedt, J., M. Bauwens, R. Tytgat, and J. De Ley. 1980. Intraand intergeneric similarities of ribosomal ribonucleic acid cistrons of free-living, nitrogen-fixing bacteria. Int. J. Syst. Bacteriol. 30:106-122.

6. De Smedt, J., and J. De Ley. 1977. Intra- and intergeneric similarities of Agrobacterium ribosomal ribonucleic acid cistrons. Int. J. Syst. Bacteriol. 27:222-240.

7. De Vos, P., and J. De Ley. 1983. Intra- and intergeneric similarities of Pseudomonas and Xanthomonas ribosomal ribonucleic acid cistrons. Int. J. Syst. Bacteriol. 33:487-509.

8. De Vos, P., M. Goor, M. Gillis, and J. De Ley. 1985. Ribosomal ribonucleic acid cistron similarities of phytopapthogenic Pseudomonas species. Int. J. Syst. Bacteriol. 35:169-184.

9. Dye, D. W. 1962. The inadequacy of the usual determinative tests for the identification of Xanthomonas spp. N. Z. J. Sci. 5:393-416.

10. Garrett, C. M. E. 1982. Bacterial diseases of food plants-an overview, p. 115-132. In M. E. Rhodes-Roberts and F. A. Skinner (ed.), Bacteria and plants. Academic Press, London.

11. Gilardi, G. L. 1971. Characterization of Pseudomonas species isolated from clinical specimens. Appl. Microbiol. 21:414-419.

12. Gillis, M., and J. De Ley. 1980. Intra- and intergeneric similarities of the ribosomal ribonucleic acid cistrons of Acetobacter and Gluconobacter. Int. J. Syst. Bacteriol. 30:7-27.

13. Hayward, A. C. 1977 . Occurrence of glycoside hydrolases in plant pathogenic and related bacteria. J. Appl. Bacteriol. 42: $407-411$.

14. Hugh, R. 1981. Pseudomonas maltophilia sp. nov., nom. rev. Int. J. Syst. Bacteriol. 31:195.

15. Hugh, R., and E. Ryschenkow. 1961. Pseudomonas maltophilia an Alcaligenes-like species. J. Gen. Microbiol. 26:123-132.

16. Ikemoto, S., K. Suzuki, T. Kaneko, and K. Komagata. 1980. Characterization of strains of Pseudomonas maltophilia which do not require methionine. Int. J. Syst. Bacteriol. 30:437-447.

17. Johnson, J. L. 1984. Nucleic acids in bacterial classification, p. 8-11. In N. R. Krieg and J. G. Holt (ed.), Bergey's manual of systematic bacteriology, vol. 1. The Williams \& Wilkins Co., Baltimore.

18. Johnson, J. L., and N. J. Palleroni. 1989. Deoxyribonucleic acid similarities among Pseudomonas species. Int. J. Syst. Bacteriol. 39:230-235.

19. Kandler, O., and K.-H. Schleifer. 1980. Systematics of bacteria. Prog. Bot. 42:234-237.

20. Komagata, K., E. Yabuuchi, Y. Tamagawa, and A. Ohyama. 1974. Pseudomonas melanogena lizuka and Komagata 1963, a later subjective synonym of Pseudomonas maltophilia Hugh and Ryschenkow 1960. Int. J. Syst. Bacteriol. 24:242-247.

21. Krawiec, S. 1985. Concept of a bacterial species. Int. J. Syst. Bacteriol. 35:217-220.

22. Krieg, N. R. 1988. Bacterial classification: an overview. Can. J. Microbiol. 34:536-540.

23. Murray, R. G. E., D. J. Brenner, R. R. Colwell, P. De Vos, M Goodfellow, P. A. D. Grimont, N. Pfennig, E. Stackebrandt, and G. A. Zavarzin. 1990. Report of the Ad Hoc Committee on Approaches to Taxonomy within the Proteobacteria. Int. J. Syst. Bacteriol. 40:213-215.

24. Oyaizu, H., and K. Komagata. 1983. Grouping of Pseudomonas species on the basis of cellular fatty acid compositions and the quinone system with special reference to the existence of 3-hydroxy fatty acids. J. Gen. Appl. Microbiol. 29:17-40.

25. Palleroni, N. J. 1981. Introduction to the family Pseudomonadaceae, p. 655-665. In M. P. Starr, H. Stolp, H. G. Trüper, A. Barlows, and H. G. Schlegel (ed.), The prokaryotes: a handbook on habitats, isolation and identification of bacteria. Springer-Verlag, Berlin.

26. Palleroni, N. J. 1984. Family I. Pseudomonadaceae, p. 141-199. 
In N. R. Krieg, and J. G. Holt (ed.), Bergey's manual of systematic bacteriology, vol. 1. The Williams \& Wilkins Co. Baltimore.

27. Palleroni, N. J. 1986. Taxonomy of the pseudomonads, p. 3-25. In J. R. Sokatch (ed.), The bacteria: the biology of Pseudomonas. Academic Press, London.

28. Palleroni, N. J., R. Kunisawa, R. Contopoulou, and M. Doudoroff. 1973. Nucleic acid homologies in the genus Pseudomonas. Int. J. Syst. Bacteriol. 23:333-339.

29. Robbs, C. F., R. de L. D. Ribeiro, and O. Kimura. 1974. Sobre a posiqao taxonomica de $P$ seudomonas mangiferaeindicae $\mathrm{Pa}-$ tel et al. 1948, agente causal da "mancha bacteriana" das folhas da mangueira (Mangifera indica L.). Arq. Univ. Fed. Rural Rio de Janeiro 4:11-14.

30. Robbs, C. F., R. de L. D. Ribeiro, O. Kimura, and F. Akiba. 1972. Variaqoes em Xanthomonas manihotis (Arthaud-Berthet) Starr. Rev. Soc. Bras. Fitopatol. 5:67-75.

31. Sabet, K. A. 1959. Studies in the bacterial diseases of Sudan crops. II. Bacterial leaf blight disease of castor (Ricinus communis L.). Ann. Appl. Biol. 47:49-56.

32. Sneath, P. H. A. 1989. Analysis and interpretation of sequence data for bacterial systematics: the view of a numerical taxonomist. Syst. Appl. Microbiol. 12:15-31.

33. Staley, J. T., and N. R. Krieg. 1984. Classification of procaryotic organisms: an overview, p. 1-3. In N. R. Krieg and J. G. Holt (ed.), Bergey's manual of systematic bacteriology, vol. 1. The Williams \& Wilkins Co., Baltimore.

34. Starr, M. P. 1946. The nutrition of phytopathogenic bacteria. I. Minimal requirements of the genus Xanthomonas. J. Bacteriol. 51:131-143.

35. Starr, M. P. 1981. The genus Xanthomonas, p. 742-763. In M. P. Starr, H. Stolp, H. G. Trüper, A. Barlows, and H. G. Schlegel (ed.), The prokaryotes: a handbook on habitats, isolation and identification of bacteria. Springer-Verlag, Berlin.

36. Starr, M. P., and W. L. Stephens. 1964. Pigmentation and taxonomy of the genus Xanthomonas. J. Bacteriol. 87:293-302.

37. Swings, J., P. De Vos, M. Van den Mooter, and J. De Ley. 1983. Transfer of Pseudomonas maltophilia Hugh 1981 to the genus
Xanthomonas as Xanthomonas maltophilia (Hugh 1981) comb. nov. Int. J. Syst. Bacteriol. 33:409-413.

38. Van den Mooter, M., and J. Swings. 1990. Numerical analysis of 295 phenotypic features of 266 Xanthomonas strains and related strains and an improved taxonomy of the genus. Int. J. Syst. Bacteriol. 40:348-369.

39. Van Zyl, E., and P. L. Steyn. 1990. Differentiation of phytopathogenic Pseudomonas and Xanthomonas species and pathovars by numerical taxonomy and protein gel electropherograms. Syst. Appl. Microbiol. 13:60-71.

40. Vauterin, L., J. Swings, K. Kersters, M. Gillis, T. W. Mew, M. N. Schroth, N. J. Palleroni, D. C. Hildebrand, D. E. Stead, E. L. Civerolo, A. C. Hayward, H. Maraite, R. E. Stall, A. K Vidaver, and J. F. Bradbury. 1990. Towards an improved taxonomy of Xanthomonas. Int. J. Syst. Bacteriol. 40:312-316.

41. Volchkevich, Z. A., and G. K. Degteva. 1989. Electrophoretic analysis of Pseudomonas exoproducts. Zh. Mikrobiol. Epidemiol. Immunobiol. 8:24-28.

42. Wayne, L. G., D. J. Brenner, R. R. Colwell, P. A. D. Grimont, O. Kandler, M. I. Krichevsky, L. H. Moore, W. E. C. Moore, R. G. E. Murray, E. Stackebrandt, M. P. Starr, and H. G. Trüper. 1987. Report of the Ad Hoc Committee on Reconciliation of Approaches to Bacterial Systematics. Int. J. Syst. Bacteriol. 37:463-464.

43. Whitaker, R. J., G. S. Byng, R. L. Gherna, and R. A. Jensen. 1981. Comparative allostery of 3-deoxy-D-arabino-heptulosonate-7-phosphate synthetase as an indicator of taxonomic relatedness in pseudomonad genera. J. Bacteriol. 145:752-759.

44. Woese, C. R., P. Blanz, and C. M. Hahn. 1984. What isn't a pseudomonad: the importance of nomenclature in bacterial classification. Syst. Appl. Microbiol. 5:179-195.

45. Young, J. M., J. F. Bradbury, L. Gardan, R. I. Gvozdyak, D. E Stead, Y. Takikawa, and A. K. Vidaver. 1991. Comment on the reinstatement of Xanthomonas citri (ex Hasse 1915) Gabriel et al. 1989 and $X$. phaseoli (ex Smith 1897) Gabriel et al. 1989 indication of the need for minimal standards for the genus Xanthomonas. Int. J. Syst. Bacteriol. 40:348-369. 